\title{
The influence of Europeanization policies on immigrants' participation in Scandinavian higher education ${ }^{1}$
}

\section{Dinah Kagan ${ }^{2}$}

\begin{abstract}
The aim of the paper is to provide further insights into the mechanisms contributing to the integration of immigrants in higher education. Recent immigration waves into Europe place pressure on European communities; However, mass immigration is only expected to increase. The immigrants' influence on their host countries depends on their economic performance and how well they adapt. In this regard education serves as a key component towards successful integration. As European higher education transforms the influence of these reforms on the participation rates of immigrants is of relevance. A comparison between the participation rates of immigrants following the Europeanization of the Scandinavian higher education system provides interesting insights to these issues.
\end{abstract}

Keywords: higher education; education and inequality; economics of minorities; equity, justice and inequality; migration, Europeanization; immigration law.

JEL codes: D63, I23, I24, K37, O15.

\section{Introduction}

Contemporary waves of mass immigration into Europe are changing the European societies as they bring challenges, as well as opportunities to the European community. From an economic perspective the impact of immigrants depends on their economic performance and how well they adapt to their host country. In this regard education serves as a key component towards integration. Furthermore, immigration pressures are expected to increase, particularly from developing countries into high-income European countries (Docquier, 2018). Yet, with about 1.3 million refugees coming to the EU in 2015, more than 50\% of which are in the age group between 18 and 34, the issue of immigrant participation in education places further pressure on efforts of integration. Nevertheless, despite significant public attention, little

\footnotetext{
${ }^{1}$ Article received 25 November 2018, accepted 21 January 2019.

2 Tel-Hai College, 1220800 Upper Galilee, Israel, dinak@telhai.ac.il.
} 
is known about the causes and processes that lead to the relative educational disadvantage of immigrants.

Moreover, for economic growth to be sustainable inclusive growth must be pursued. One of the non-monetary aspects of inclusive growth is education as rapid changes in the labour market alongside the increased competition for jobs may result in the risk that lower-skilled social groups are left behind (Busemeyer, 2018; Darvas \& Wolff, 2016). Consequently, higher education (HE) participation has been transformed from a privilege to a necessity, as it becomes a key instrument in obtaining social justice, maintaining national economic growth and individual development. Thus over the recent decades HE systems have seen a massive expansion worldwide and the transformation to a high level of participation is leading to alterations in the role of $\mathrm{HE}$ and the composition of the student body (Marginson, 2016).

Various related processes have influenced contemporary European HE: Cultural globalization in terms of ideological convergence of norms and values such as mobility, internationalization, equity, social efficiency and democracy are being promoted by international agencies. The question arises as to what extent these trends have contributed to increasing the participation of disadvantaged groups in higher education? This research focuses on the Europeanization processes of HE which occur when HE systems and organizations adapt to environmental pressures coming from European initiatives (Vukasoavić, 2013). Europeanization processes such as the Bologna Process and the Lisbon strategy have led to increased emphasis on inclusion and to the introduction of shorter degree courses that allow students to enter the labour market more rapidly. These reforms have not gone uncriticized and particularly the Bologna Process has been blamed for declining academic quality as a result of the new degree system. Nonetheless this study is an attempt to shed some light on the impact of Europeanization processes on inclusion by reviewing their impact on immigrant participation in HE.

Previous research on the impact of Europeanization reforms on under-represented groups tends to focus on students from a low socio-economic origin (Neugebauer, Neumeyer, \& Alesi, 2016) traditional one-cycle degree programs have been re-arranged into two successive cycles (bachelor's and master's. Berton and Bondonio (2018) discuss the influence of the Bologna degree reform on overall enrolment rates. However, research on how the degree structural change influenced HE participation is scarce and somewhat inconclusive indicating that the effect differs across countries (Di Pietro, 2011, p. 358). To the best of the knowledge of the author no research has focused on the effects of the structural reforms on immigrant enrolment in general and in Scandinavia in particular. Furthering our knowledge of the mechanisms that encourage increased participation of immigrants in higher education, may elucidate the successful mechanisms for the integration of immigrants. Thus the study aims to contribute to existing scholarship both in the research of immigrants' inte- 
gration through higher education and the potential role that Europeanization processes may play in the integration of immigrants.

The rest of the paper is organized as follows: Section 1 deals with the problem of immigrant educational inequalities and Europeanization processes in higher education. Section 2 elaborates on the methodology of the research. Section 3 investigates the influence of Europeanization process in Scandinavian higher education on the participation of immigrants. The paper is closed with conclusions.

\section{Background}

In an attempt to address research gaps this study's concept is based on immigrant-related educational inequality theories, as well as Europeanization theories. This section reviews the most prominent concepts related to those dimensions before turning to the research of immigrants and their participation in each of the Scandinavian countries.

\subsection{Immigrant related educational inequalities}

Educational inequalities are related to the individual's socio-economic background as economic, social and cultural forms of capital are intergenerationally transmitted and the educational systems operate as a primary mechanism in the perpetuation of socio-economic inequality. Extensive research is devoted to educational inequalities in the education systems (Thomson, 2017). From the perspective of higher education attention has been drawn to the inclusion of under-represented groups and how such groups are affected by the expansion processes of HE (Arum, Gamoran, \& Shavit, 2007; Neugebauer et al., 2016; Thomson, 2017). Marginson (2016) suggests equity in HE consists of two dimensions: inclusion and fairness. Inclusion refers to the overall increase in participation of under-represented groups, whereas fairness refers to their proportional representation in comparison with other social groups. Additionally, combined with expansion processes, the stratification and diversification of HE divert less-advantaged individuals to low-prestige programmes making the inequality more subtle.

Persons with an immigrant background are identified in the research as an under-represented group in $\mathrm{HE}$ as they often experience educational inequalities which are partially related to their socio-economic status and partially related to their immigrant background. Research of the immigrants' educational achievements tends to focus on the primary and secondary effects on HE attainment (Griga \& Hadjar, 2013). Primary effects are all socio-cultural factors that are expressed in the academic performance of children. Secondary effects, on the other hand, are socio-cultural factors that are expressed in the educational 
choices of the individual. Secondary effects are the focal point of immigrantrelated research with immigrants' high aspirations viewed as a crucial component in their decision to continue to HE (Crul, Schneider, Keskiner, \& Lelie, 2016). The influence of secondary effects in the context of under-represented groups has been examined with regard to a transition into upper-secondary education (Dollmann, 2017).

In the cost-benefit model for predicting how different social groups react to increasing educational opportunities (Jonsson \& Erikson, 2007), the benefits versus the costs and the probability of success are considered. HE expansion, in itself, did not increase equity, though it has contributed to social mobility. However, drawing on the cost-benefit model it is plausible to assume that shortening degree time would lead to increased participation of under-represented groups. Furthermore structural elements, predominantly stratification among institutions and programmes are recognized as a prime cause for immigrant education inequality (Griga \& Hadjar, 2013). Attention has been drawn to the earlier stages of stratification at elementary or secondary school level (Dollmann, 2017). Less attention has been given to the effects on the educational transition decisions of young immigrants as a result of changes in the structures of HE.

Typically identified as a less advantaged social group the increased participation of immigrants and their descendants in $\mathrm{HE}$ is vital for their integration and social inclusiveness. In general, it has been shown that second-generation immigrants tend to exhibit higher educational achievements than their native-counterparts of the same generation. Respectively the educational and labour market paths of children with an immigrant background is less influenced by their parents in comparison with their native-counterparts of a similar socio-economic background (OECD, 2018, p. 10). This phenomenon has been named the 'immigrant paradox' and is primarily discussed in American literature (Hofferth \& Moon, 2016). Whether the immigrant paradox applies across socio-economic and ethnic groups remains a matter of debate (Feliciano \& Lanuza, 2017, p. 213). Institutional settings and non-stratified and comprehensive education systems were found to improve the educational prospects of immigrants. Moreover a multiplier effect appears to operate on second-generation immigrants in which they tend to take more advantage of structural features and indirect routes than their native counterparts, thus increasing their accumulation of social and cultural capital (Crul et al., 2016). Educational institutional arrangements are particularly influential on this group. Nonetheless, research on immigrant educational inequalities is lacking and the scarcity of high-quality data related to immigrants in $\mathrm{HE}$ is one of the reasons for this (Camilleri, Griga, \& Mühleck, 2013). 


\subsection{Europeanization of Scandinavian higher education}

Europeanization processes are defined as the construction, diffusion and institutionalization of formal and informal rules defined in the EU policy (Radaelli, 2002). This definition was further elaborated to include European non-EU intergovernmental processes such as the Bologna Process and attention was drawn to the intersection between national HE policies and Europeanization processes (Maassen \& Musselin, 2009; Vukasoavić, 2013). To a large extent reforms in European HE systems during the first decades of the millennium have been attributed to Europeanization processes. Among the most prominent is the Bologna Process. The varied pace and extent of implementation of the Bologna objectives provide valuable insights into the intersection between Europeanization and national agenda.

Launched in 1999 the Bologna Process aimed at establishing a European Area of $\mathrm{HE}$ and as such provides a means of mainstreaming HE activities towards similar overarching policies. To harmonize European HE systems a set of objectives was defined. These included, among others, the introduction of the two and later three-cycle degree system. The Bologna Process served as an umbrella for common purpose HE policies and its aim was to remove educational borders. On the other hand the Bologna Process also served as an opportunity for national governments to conduct reforms of their HE systems and Bologna was strategically used as a golden opportunity to justify reforms in sensitive areas (Sin \& Saunders, 2014). Thus, in spite of a varied pace of implementation, European HEIs have become more integrated and standardized under the Bologna Process. Before Bologna each Scandinavian country had developed its own solutions to the increasing scope and internationalization of HE. Following the Bologna Process Scandinavian countries changed their degree systems in accordance with Bologna guidelines. However, due to their national disparities Bologna objectives were implemented at a different pace and with national variations.

Similarly, extensive reforms in Scandinavian HE were partially driven by a national agenda and partially motivated by the need to conform to European norms. Norway and Denmark were motivated by the economic need to shorten study duration and bring graduates into the labour market sooner while the Bologna degree reform in Sweden was more motivated by the need to conform to European standards (Lindberg-Sand, 2007; Sin \& Saunders, 2014). Nonetheless in all three countries the need to conform to European standards played an important role in the final implementation of degree reform. Regardless of convergence towards European norms and values some national HE characteristics have prevailed. Danish HE remained relatively segmented though its level of flexibility has improved, predominantly in professional programmes. Sweden maintained its uniform system although the Bologna structure provides a more rigid framework than its prior degree system. Finally, 
Norwegian HE remained binary although with increased transition opportunities.

\section{Methodology}

This research focuses on the three Scandinavian countries (Denmark, Sweden and Norway) as a case study for a comparison of the influence of reform due to their similar settings but the different pace of reform implementation. As such Scandinavia provides an interesting platform for an examination of the reform's impact. Furthermore, all three countries share common linguistic, cultural and historical similarities as well as a common model of education with a comprehensive primary school system through grade 9 and generous grant/loan systems for all students. Moreover, all three countries have strong and successful competitive economies with high immigration flows and parallels in their historical immigration policies and trends.

In accordance with research objectives the influence of the reforms on immigrant participation is examined with a focus on changes to the two dimensions of equity: inclusion and fairness (Marginson, 2011) (for further discussion see section 1.1). The research uses quantitative methods in which secondary data from longitudinal national Student Registers, covering the years before during and after the implementation of the Europeanization policies, ${ }^{3}$ are analyzed. The time scope of the empirical analysis encompasses the different pre-postdegree reform years in Denmark, Sweden and Norway spanning from 1991 to 2016. Given the limitations of comparable data on immigrant participation in $\mathrm{HE}$ and the different pace and extent of implementation of reforms the empirical study uses the case study method rather than direct comparison. Hence, Tables 1-3 display results of each country's analysis according to the relevant time-span of its implementation of the reforms. The effect of the introduction of the bachelor's degree on participation trends is measured by means of a linear regression model using R-studio implemented on longitudinal data at country level (Berton \& Bondonio, 2014). The purpose of using this model is to identify whether an effect of the reform years on the proportional participation of persons with an immigrant background can be identified.

The main challenge for the analysis of reform impact is to separate the reform impact from other effects produced by other factors related to demographic, student composition or labour market aspects (Berton \& Bondonio,

\footnotetext{
${ }^{3}$ Europeanization policies in Scandinavian higher education took place at different times. Hence the data analyzed for each country refers to the country-relevant Europeanization timeframe. In the case of Denmark reform was introduced in 1993 and fully implemented by 2003; in the case of Sweden reform was set in motion in 2002 and finalized in 2007; and finally Norway launched the change in 2003 and finalized the reform in 2007.
} 
2018). Previous research on the influence of the new degrees on participation patterns focuses on the general population and is mostly limited to one country (Bondonio \& Berton, 2018; Di Pietro, 2011; Cappellari \& Lucifora, 2009).

\section{Changes in participation trends of persons with an immigrant background in Scandinavian $\mathrm{HE}$}

In the last forty years Scandinavia has experienced large scale immigration of rather similar patterns. Nonetheless, essential disparities in immigration policies and the composition of the immigrant population should be pointed out as immigration inflow patterns reflect those differences (Pettersen \& Østby, 2013, p. 77). Denmark with the strictest immigration policy has experienced an increase of $141 \%$ in immigration inflow though it is behind Norway and Sweden. Starting in 2010 Norway has adopted a stricter immigration policy which has led to a more moderate inflow. Finally Sweden's liberal policy is mirrored in the high increase of immigration - of more than 200\% (OECD, 2017).

Since the 1970's Scandinavian immigration policy was aimed at restricting un-skilled immigration while allowing the admission of skilled workers in demand. Subsequently in the first half of 2000 refugees or family reunifications became the two main immigration groups in Scandinavia. With immigrant and refugee numbers continually increasing across Europe and Scandinavia the issue of immigrant integration and HE participation becomes a pressing matter. Immigration may pose economic and cultural challenges to the host countries. Immigration influence may vary according to the level of education and skill of the newcomers. Furthermore, the long-term economic impact of immigration depends on the integration of the immigrants in the native society.

\subsection{Denmark}

Denmark is the Scandinavian country with the strictest immigration and integration policy. Since the beginning of the millennium Denmark has shifted from a relatively open immigration policy to one of the most closed immigration policies in Europe (Mailand, 2017, p. 92). The new Centre-Right coalition modified control and access policies, including the elimination of the de facto refugee category and age restrictions for married couples.

Between 1991-2015 the composition of the Danish population changed, while people of Danish origin made up 95\% of the total population in 1991, their share decreased significantly over the years. By 2015 immigrants and descendants were $11.6 \%$ of the entire Danish population, 9\% immigrants and 3\% descendants. Among the group with an immigrant background $53 \%$ originate from European countries, making it the largest immigrant group. The second largest group are immigrants from Asia and the third largest group are immi- 
grants from Europe outside the EU-28 (incl. Norway and Turkey) (Statistics Denmark, 2016). Among the descendants the two largest groups originate from Asia and Europe outside the EU-28. Over time the largest descendant group has become the Asian group. Concerning the country of origin the largest immigrant group originates from Turkey with 9.4\% immigrants and descendants, followed by Poland and Germany.

\section{Participation Trends in HE}

Data on the student participation in Denmark is taken from the Student Register-a longitudinal register that follows the educational career of each student throughout all educational programmes. The inclusion dimension in the Danish HE system in respect to persons of an immigrant background is measured by entry rates (\#student per sub- population/100,000 of sub-population) for each sub-population and various HE types. Growth in HE entry is evident for all groups (Figure 1). However, most apparent is the increase in the inclusion of descendants. With regard to the group of immigrants the trend of constant increase was reversed in 2013.

\section{Inclusion all groups}

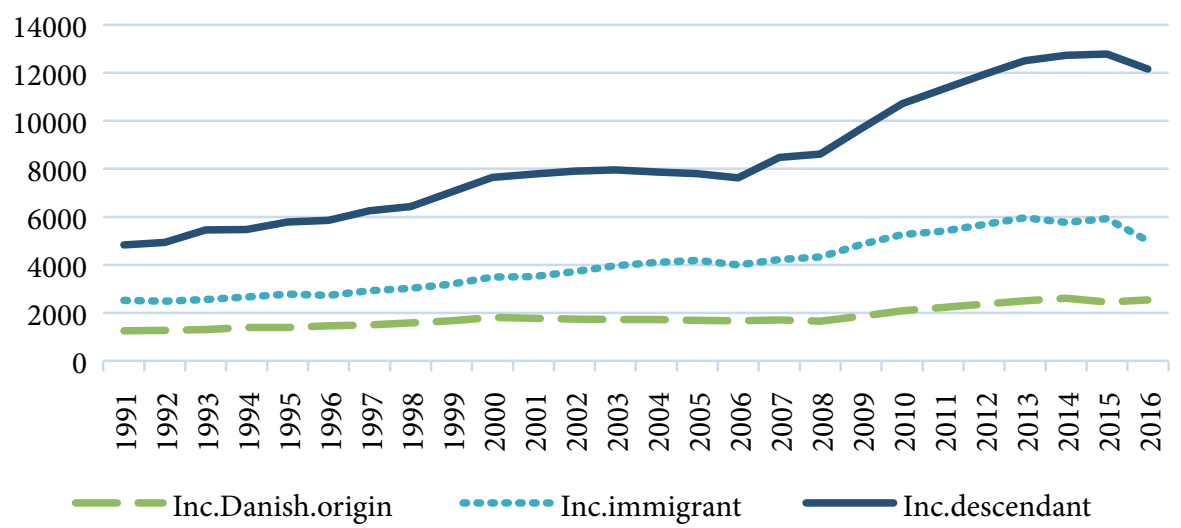

Figure 1. Inclusion trends by population, Denmark, 1991-2016 Source: Based on (Statistics Denmark, 2017).

The fairness dimension of equity demonstrates the representation of each group in relation to its proportion in society and the student body. The fairness dimension is calculated as follows:

$$
\text { Equity }=\frac{\# \text { students.subgroup } / \text { Students.total }}{\# \text { Citizens.subgroup } / \# \text { Citizens.total }}=\frac{p_{\text {students,subpopulation }}}{p_{\text {citizens,subpopulation }}}
$$


Equity $>1$ meaning over-representation in the student population,

Equity $<1$ meaning under-representation in the student population,

The equity line ( $\mathrm{a}=1$, dashed line) is included for reference.

The Fairness analysis (Figure 2) indicates that the descendants have benefited the most from the education system. This group was over-represented in 1991 before the implementation of the reforms yet the over-representation has further increased during the reform years. At a more moderate level the immigrant group began at the level of equitable representation, decreasing to slight under-representation but since the millennium the trend has changed to a substantial over-representation. In 2008 this trend changed again although a level of slight over-representation was maintained. The major part of the student body consisting of Danish-origin students remained relatively constant over time. Descendant over-representation is evident at all levels of education although there has been a constant downward trend in the Longcycle education. This result may indicate that the second-generation students chose to leave to enter the labour market upon completion of the first cycle of education.

Fairness all groups

6

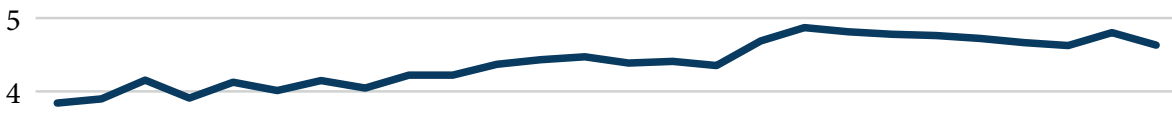

3
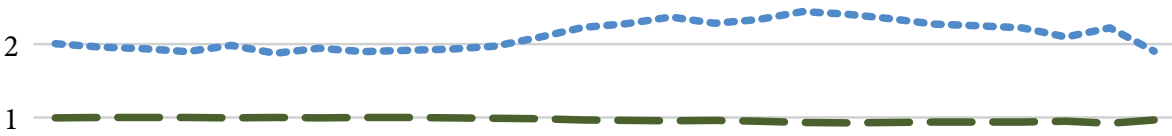

0

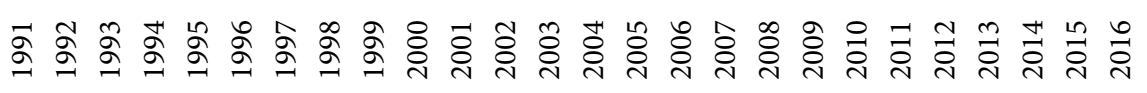

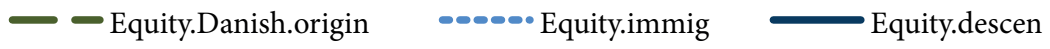

Figure 2. Fairness Trends by Population, Denmark, 1991-2016

Source: Own analysis based on data from (Statistics Denmark, 2017).

A further examination is required to evaluate the representation trend over time (representing reform years) and the effect of HE type. In order to assess this an OLS model was built for each sub-population, with the fairness dimension as the equity measure (as described above) being explained as a variable. 


$$
\begin{aligned}
& y_{i}=\beta_{0}+\beta_{1} *\left(\text { year }- \text { year }{ }_{0}\right)+\beta_{2}{ }^{*} I_{\text {Short-cycle }}+\beta_{3}{ }^{*} I_{\text {Medium-cycle }}+\beta_{4}{ }^{*} I_{\text {Long-cycle }}+ \\
& +\beta_{12}{ }^{*}\left(\text { year }- \text { year } r_{0}{ }^{\star} I_{\text {Short-cycle }}-\text { cycle }+\beta_{13}{ }^{\star}\left(\text { year }- \text { year }_{0}\right) * I_{\text {Medium-cycle }}+\right. \\
& +\beta_{14} *\left(\text { year }- \text { year }_{0}\right) * I_{\text {Long-cycle }}+\varepsilon_{i} \\
& \text { reference_level }=\text { "Bachelor" }
\end{aligned}
$$

The Bachelor: the group of interest (new degree), serves as reference. $\beta_{1}$ is the correction for the effect of time (on all groups), due to unknown/unobserved factors from the first year of data (i.e. year-year ${ }_{0}$ defined as "year.centred"). This definition was motivated by a need to improve model readability by decreasing the co-variance between the intercept and the year variable by centring the time. The coeffients $\left[\beta_{2}, \beta_{3}, \beta_{4}\right]$ are the main effects of the different type of $\mathrm{HE}$ (each multiplied by a relevant indicator variable). The coefficients $\left[\beta_{12}, \beta_{13}, \beta_{14}\right]$ are the interaction effects between year and each of the higher eduction types. This seemed plausible as the reform was implemented over several years with presumably different effect $-\varepsilon_{\mathrm{i}}$ represents the errors of the model. Note-the analysis using an ARIMA model (auto.arima function in R) did find an $\mathrm{AR}(1)$ model to fit the data. However it did not account for the intrinsic dependence of errors (in contrast to the usual OLS where $\varepsilon_{i}^{i i d} \sim N\left(0, \sigma^{2}\right)$ due to the need to maintain model simplicity and undestandbility and to the fact that not accounting for the dependence of errors actually inflates the Standard Error (SE) of the coefficients, thus making the hypothesis testing regarding the coefficienct more conservative.

The first model analyzing immigrant participation (Table 1) significantly explains $(p$-value $<0.0001)$ a significant part of the variance $(67.12 \%)$. In this model no main influence of time (year) or type of HE is identified. In other words, no change in the general proportional representation was identified, nor in the different types of HE over the years. However, an inspection of the interaction effects provides additional insight.

As the model progresses in time an upward trend can be identified for the Short-cycle (0.051) and the Long-cycle (0.037). The increase in the Short-cycle education is not linear (as assumed by the model) but given the accuracy of fit measures it appears that the overall trend is indeed captured by the model. This might reflect the application of new programmes and a possible shift of other sub-populations towards other, new academic tracks (consistent with the observed decrease in equity for the immigrants) and consequently an increased representation of immigrants. The model reflects an effect particularly evident in the short and long cycles. However, over time the change is moderated. Furthermore, for the Bachelor programmes, the model shows a short -time effect of increase above the equity line although this trend is reversed after 2005.

The proposed model for descendants' participation trends (Table 1) clearly explains $(p$-value $<0.0001)$ a significant part of the variance $(75.98 \%)$. Here the 
Table 1. Denmark-reform influence model summary, 1991-2016

\begin{tabular}{|c|c|c|c|c|}
\hline \multirow{9}{*}{$\begin{array}{l}\text { Sub-population } \\
\text { immigrants }\end{array}$} & & Estimate & $p$-value & $p$-model \\
\hline & $\beta 0$ (Intercept) & 0.885821 & $<0.0001$ & $<0.0001$ \\
\hline & $\beta 1$ (year.centred) & 0.001738 & 0.8242 & $R^{2}$ \\
\hline & $\beta 2$ (Short-cycle) & 0.1685170 & 0.2974 & 0.61720 \\
\hline & $\beta 3$ (Medium-cycle) & -0.084415 & 0.6009 & \\
\hline & $\beta 4$ (Long-cycle) & 0.135182 & 0.4027 & \\
\hline & $\beta 12$ (year.centred ${ }^{\star}$ Short-cycle) & 0.050589 & $<0.0001$ & \\
\hline & $\beta 13$ (year.centred ${ }^{\star}$ Medium-cycle) & 0.013246 & 0.2329 & \\
\hline & $\beta 14$ (year.centred ${ }^{\star}$ Long-cycle) & 0.037133 & 0.0011 & \\
\hline \multirow{9}{*}{$\begin{array}{l}\text { Sub-population } \\
\text { descendants }\end{array}$} & & Estimate & $p$-value & $p$-model \\
\hline & $\beta 0($ Intercept $)$ & 2.863961 & $<0.0001$ & $<0.0001$ \\
\hline & $\beta 1$ (year.centred) & -0.000187 & 0.981396 & $R^{2}$ \\
\hline & $\beta 2$ (Short-cycle) & -0.77579 & $<0.0001$ & 0.7598 \\
\hline & $\beta 3$ (Medium-cycle) & -1.666953 & $<0.0001$ & \\
\hline & $\beta 4$ (Long-cycle) & -0.61902 & $<0.0001$ & \\
\hline & $\beta 12$ (year.centred ${ }^{\star}$ Short-cycle) & 0.04252 & $<0.0001$ & \\
\hline & $\beta 13$ (year.centred ${ }^{\star}$ Medium-cycle) & 0.065537 & $<0.0001$ & \\
\hline & $\beta 14$ (year.centred ${ }^{\star}$ Long-cycle) & -0.031401 & 0.004 & \\
\hline \multirow{9}{*}{$\begin{array}{l}\text { Sub-population } \\
\text { Danish origin }\end{array}$} & & Estimate & $p$-value & $p$-model \\
\hline & $\beta 0$ (Intercept) & 0.9993532 & $<0.0001$ & $<0.0001$ \\
\hline & $\beta 1$ (year.centred) & -0.0004594 & 0.5219 & $R^{2}$ \\
\hline & $\beta 2$ (Short-cycle) & 0.0065985 & 0.6553 & 0.7698 \\
\hline & $\beta 3$ (Medium-cycle) & 0.0205749 & 0.166 & \\
\hline & $\beta 4$ (Long-cycle) & 0.011034 & 0.456 & \\
\hline & $\beta 12$ (year.centred ${ }^{\star}$ Short-cycle) & 0.04252 & $<0.0001$ & \\
\hline & $\beta 13$ (year.centred ${ }^{\star}$ Medium-cycle) & 0.065537 & $<0.0001$ & \\
\hline & $\beta 14$ (year.centred ${ }^{\star}$ Long-cycle) & -0.031401 & 0.004 & \\
\hline
\end{tabular}

trends are different-during the reform years several trends may be observed: While there was no central time effect the dominant influence is identified in the shift in representation rates between tracks-a significant reduction in equity levels in all non-bachelor tracks with the most significant in the Medium-cycle. Inspection of interaction terms provides a more comprehensive overview-the main negative effects for the Short-cycle and Medium-cycle were moderated 
in time (and even compensated for) whereas the negative effect for the Longcycle was enhanced over time. With respect to the second-generation analysis indicates upward trends in all programmes but the long-term degree.

The proposed model for the Danish-origin students (Table 1) significantly explains ( $p$-value $<0.0001)$ a major part of the variance $(76.98 \%)$. When looking for specific effects no main effect, either for time (year) or type of HE is identified. However an examination of the interaction effects provides an additional insight-in reality as the model progresses in time, the increase in equity for the short cycle decreased $(-0.0068)$ and same for the Long-cycle $(-0.004)$. In conclusion, analysis of participation trends of the Danish population during reform years exposes different trends for first and second-generation immigrants. Nevertheless, an increase in the participation rates of persons with immigrant background is identified during reform years. Actual effect of the reform is most evidently identified for the second-generation.

\subsection{Sweden}

Of all the three Scandinavian countries Sweden has the most liberal refugee, immigration, and integration policy. Though Sweden also restricted its immigration policy it was not to the extent of Norway or Denmark. Until 2010 Swedish integration policy emphasized immigrants' rights rather than duties. At that stage conditionality was introduced in the reforms to labour work introduction support. During the first years of the millennium, the immigrant percentage in the Swedish population increased significantly. Sweden's' liberal immigration policy in comparison to the other Scandinavian countries is reflected in the relatively high proportion (30\%) of immigrants. Over the course of the last fifteen years the total Swedish origin population has decreased to $70 \%$ (Statistics Sweden, 2016). Additionally, the composition of the immigrant population has changed over the last 15 years. In 2015 almost 163,000 people from Syria and Afghanistan applied for asylum in Sweden. This dramatic increase in asylum-based immigration led Sweden to introduce a stricter immigration policy.

\section{Participation trends in $\mathrm{HE}$}

Data on immigrant participation in Swedish HE is taken from the Register on Participation in Education of Statistics Sweden. The data does not provide separation between the educational cycles and analysis is therefore limited to an examination of participation in the general HE. The timeframe for the analysis is based on the timeframe for the reforms. Inclusion and fairness participation in Swedish HE for each sub-population are presented in Fig. 3. While the descendants exhibit an upward trend the trend of immigrant participation has decreased since 2010. This reverse trend may be connected to the dramatic increase in asylum immigration in those years. 


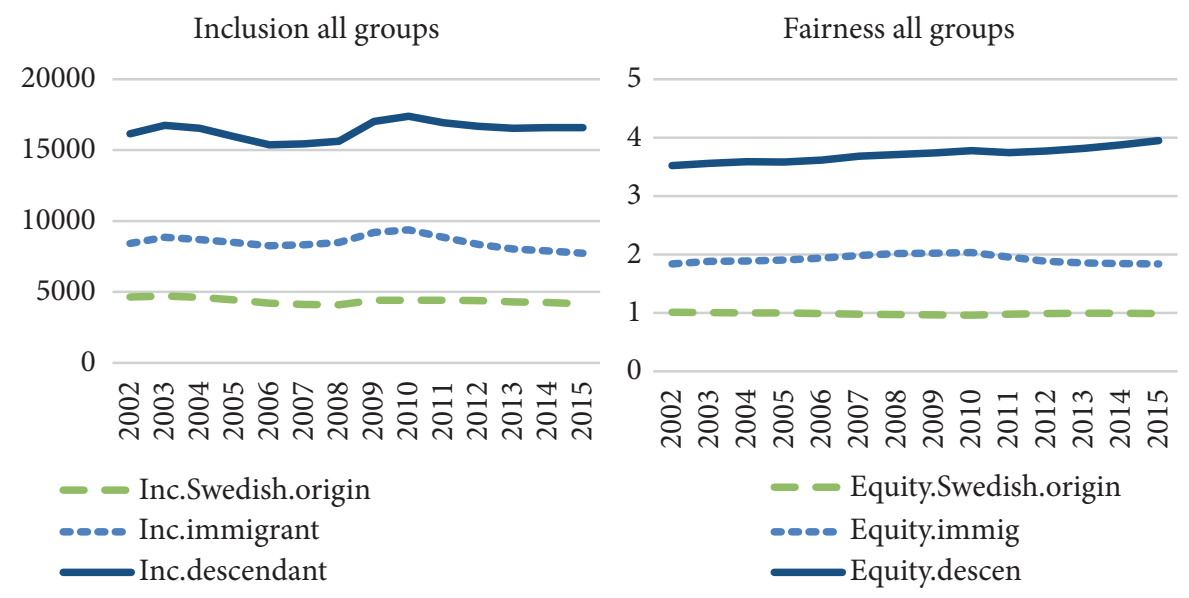

Figure 3. Equity trends by population, Sweden, 2002-2015

Source: Based on (Statistics Sweden, 2017).

The effect of reform on participation trends of sub-population-based on the data from national Student Register a quadratic OLS model was developed with fairness measure being the explained variable.

$$
y_{i}=\beta_{0}+\beta_{1} \cdot\left(\text { year }- \text { year } r_{0}\right)+\beta_{11} \cdot\left(\text { year }- \text { year }_{0}\right)^{2}+\varepsilon_{i} .
$$

In this model $\beta_{1}$ (Table 2. Sweden- Reform Influence Model Summary, 20022015 ) is the correction for the effect of time due to unknown/unobserved factors depending of how many years have passed since the first year in the database (year-year $\left.{ }_{0}\right) \cdot \beta_{11}$ is the coefficient for the quadratic effect of time $\left(\text { year-year }{ }_{0}\right)^{2} \cdot \varepsilon_{i}$ represents the errors of the model. Note-analysis using an ARIMA model (auto. arima function in R) did find an AR(1) model to fit the data. However the intrinsic dependence of errors (in contrast to the usual OLS where $\varepsilon_{i} \sim N\left(0, \sigma^{2}\right)$ ) was not accounted for due to the need to maintain model simplicity and understandbility and to the fact that not accounting for the dependence of errors actually inflates the Standard Error (SE) of the coefficients, thus making the hypothesis testing regarding the coefficienct more conservative.

All models and coefficients were significant $(p<0.05)$. The addition of the interaction term (year-year $\left.{ }_{0}\right)^{2}$ significantly improved each model's accuracy of fit as was demonstrated by the Adj. R-squared statistics (results of models without interaction not shown). Distinct attention is drawn to the contribution of the interaction for each model. Immigrants: The model significantly explains $73.80 \%$ of the variance in immigrants' equity. It does seem that there was an increase in proportional representation above equity 1 level, with a model peak (i.e. quadratic equation extremum when $a=-0.005<0$ ) at around 2010. There was a consistent increase until 2010 with consistent decline until 2014. Descendants: The model significantly explains $98.10 \%$ of the variance in de- 
Table 2. Sweden-reform influence model summary, 2002-2015

\begin{tabular}{|l|l|c|c|c|}
\hline \multirow{4}{*}{$\begin{array}{l}\text { Sub-population } \\
\text { immigrants }\end{array}$} & Estimate & $\boldsymbol{p}$-value & $\boldsymbol{p}$-model \\
\cline { 2 - 5 } & $\beta 0$ (Intercept) & 0.803 & $<0.0001$ & 0.0002 \\
\cline { 2 - 5 } & $\beta 1$ (year.centred) & 0.065 & $<0.0001$ & $R^{2}$ \\
\cline { 2 - 5 } & $\beta 11$ (year. centred^2) & -0.005 & $<0.0001$ & 0.738 \\
\hline \multirow{4}{*}{$\begin{array}{l}\text { Sub-population } \\
\text { descendants }\end{array}$} & $\beta 0$ (Intercept) & Estimate & $p$-value & p-model \\
\cline { 2 - 5 } & $\beta 1$ (year.centred) & 1.713 & $<0.0001$ & $<0.0001$ \\
\cline { 2 - 5 } & $\beta 11$ (year.centred^2) & -0.030 & $<0.0001$ & $R^{2}$ \\
\hline \multirow{4}{*}{$\begin{array}{l}\text { Sub-population } \\
\text { Swedish origin }\end{array}$} & $\beta 0$ (Intercept) & 0.005 & $<0.0001$ & 0.981 \\
\cline { 2 - 5 } & $\beta 1$ (year.centred) & -0.011 & 0.0002 & $R^{2}$ \\
\cline { 2 - 5 } & $\beta 2$ (Short-cycle) & 0.001 & $<0.000386$ & 0.743 \\
\hline
\end{tabular}

scendants' proportional representation which consistently remains above equity level. The fitted quadratic model further supports the continuous increase with a small trough (i.e. quadratic equation extremum when $\mathrm{a}=0.005>0$ ). Swedish origin: The model significantly explains $74.30 \%$ of the variance of the proportional representation of the population of Swedish origin, fluctuating closely to equity level 1 reflecting the dominance of this sub-population. There is a reciprocal trend between the Swedish population and the immigrants in the equity aspect and possibly also between the immigrants and the descendants (although they were not directly compared). Given the comparable sizes of the immigrant and descendant sub-populations this might represent a transition between the representation of immigrants and descendants.

\section{Norway}

In the first decade of the millennium the immigrant portion in Norwegian society increased dramatically from $5 \%$ to $12 \%$. Today the total share of persons with an immigrant background is $16.8 \%$ (SSB, 2017). The first years were characterized by family reunification and protection immigration from Asia and Africa (Statistics Norway, 2016a). After 2005 the main immigration was labour immigration particularly since the expansion of the EU in 2004 (Pettersen \& Østby, 2013). Waves of recent asylum seekers from Syria and elsewhere have further hardened the conditions for obtaining citizenship. Since 2015 Norway has restricted asylum seeker numbers to 8,000/year and introduced strict conditions resulting in a drop of $95 \%$ in applications. The share of immigration from Asia/Africa and Eastern Europe increased turning them into the two largest immigrant groups in Norway. Western European and Scandinavian immigra- 
tion also increased but not to the same extent. Between 2003 and 2007 Polish labour immigrants became the largest immigrant group in Norway followed by Lithuania and the Scandinavian countries.

Trends in immigrant participation in HE

Data on student participation in Norwegian HE is provided by Statistics Norway. The data includes all students in all three cycles of HE. Participation statistics are divided into short education $(\leq 4)$ and longer education $(>4)$. Students classified as "Unknown" were assigned to the immigrant group as this group includes students without ID \#, who are students not born in Norway. The joint group was renamed "student.immigrants.new" and "immigrants.population.new." Inclusion trends indicate a constant and sharp increase in the representation rates of descendants in Norwegian HE. Similarly to Denmark and Sweden the immigrant group increased its participation rates until 2005 when the trend changed downward. Results are in line with the increase in labour immigration in those years. Overall the dimension of immigrant inclusion did not change during the reform years.

A closer examination of participation trends according to programme length (Figure 4) exhibits similar trends. However, in the short program trends are more moderate especially for the groups of Norwegian origin and immigrants. Descendants have maintained their continual rate of growth whereas trends in immigrant participation shifted to downwards around 2005. In the longer studies these trends are further moderated. In $\mathrm{PhD}$ studies the patterns are rather different as the immigrant group is the most dominant. This may be as a result of the immigrant group composition. It is possible to assume that the 'unknown' group included in the immigrant group is, to a large extent, made up of international students, since this is one of the most plausible explanations for the lack of ID \#.
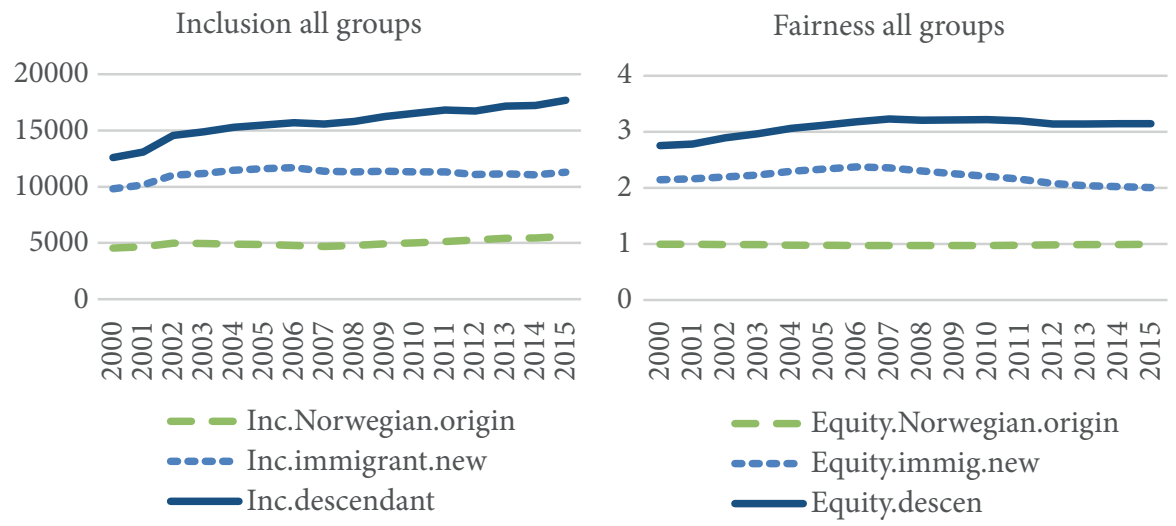

Figure 4. Equity trends by population, Norway, 2000-2015

Source: Based on (Statistics Norway, 2016b). 
In order to evalute the trend in time and the effect of higher eduction type two alternative OLS models were built for each type of sub-population, based on the trends in the data with equity measure being an explained variable:

Equity $>1$ meaning over-representation in the student population, Equity $<1$ meaning under-representation in the student population, The equity line ( $\mathrm{a}=1$, dashed line) was included for reference.

Model 1 (for immigrants)

$$
y_{i}=\beta_{0}+\beta_{1} \cdot\left(\text { year }- \text { year }_{0}\right)+\beta_{2} \cdot I_{>4-\text { years }}+\beta_{3} \cdot I_{P h D}+\beta_{11} \cdot\left(\text { year }- \text { year }_{0}\right)^{2}+\varepsilon_{i}
$$
reference_level $=" \leq 4-$ years"

Model 2 (for descendants and Norwegian origin)

$y_{i}=\beta_{0}+\beta_{1} \cdot\left(\right.$ year - year $\left._{0}\right)+\beta_{2} \cdot I_{>4-\text { years }}+\beta_{3} \cdot I_{P h D}+$

$+\beta_{12} \cdot\left(\right.$ year - year $\left.r_{0}\right) \cdot I_{>4-\text { years }}+\beta_{13} \cdot\left(\right.$ year - year $\left._{0}\right) \cdot I_{P h D}+\varepsilon_{i}$ In this model: reference_level $=" \leq 4-$ years"

The " $\leq 4$ years" group, the group of interest, serves as reference. $\beta_{1}$ is the correction for the effect of time since the first year of measurement (year ${ }_{0}$ ) $\left[\left(\right.\right.$ year-year $\left.\left._{0}\right)\right]$ (on all groups) due to unknown/unosberved factors. The coeffients $\left[\beta_{2}, \beta_{3}\right]$ are the main effects of the different type of HE (each multiplied by a relevant indicator variable). The coefficient $\left[\beta_{11}\right]$ is the quadratic effect of $\left(\right.$ year-year $\left._{0}\right)\left[\left(\text { year-year }_{0}\right)^{2}\right]$. The coefficients $\left[\beta_{12}, \beta_{13}\right]$ are the interaction effects between (year-year ${ }_{0}$ ) and each of the higher eduction types. This seemed plausible as the reform was implemented over several years with presumbly different effects. $\varepsilon_{i}$ represents the errors of the model. Note: analysis using an ARIMA model (auto.arima function in R) did find an AR(1) model to fit the data. However, the intrinsic dependence of errors (in contrast to the usual OLS where $\varepsilon_{i} \sim N\left(0, \sigma^{2}\right)$ ) due to the need to maintain model simplicity and undestandbility and to the fact the not accounting for the dependence of errors actually inflates the Standard Error (SE) of the coefficients was not accounted for, thus making the hypothesis testing regarding the coefficienct more conservative.

The proposed model (Table 3 ) significantly explains ( $p$-value $<0.0001)$ practically the entire variance $(99.1 \%)$. Immigrant participation trends reflect an upward followed by a downward trend. When examining specific effects a peak in proportional representation around 2007 (the final year of reform implementation) is shown nicely reflected in a significant quadratic time effect $(-0.006$, $p$-value $<0.0001)$.

$\mathrm{Ph}$.D. proportional representation remains relatively high and stable through the years with the reservation that students classified as "unknown" who were included in the immigrant's new group account for roughly $9 \%$ of them. These 
Table 3. Norway-reform influence model summary, 2002-2015

\begin{tabular}{|c|c|c|c|c|}
\hline \multirow{6}{*}{$\begin{array}{l}\text { Sub-population } \\
\text { Immigrants } \\
\text { new }\end{array}$} & Referene level $\leq 4$-years & Estimate & $p$-value & $p$-model \\
\hline & $\beta 0$ (Intercept) & 1.027 & $<0.0001$ & $<0.0001$ \\
\hline & $\beta 1$ (year.centred) & 0.071 & $<0.0001$ & $R^{2}$ \\
\hline & $\beta 2$ (> 4-years) & 0.392 & $<0.0001$ & 0.991 \\
\hline & $\beta 3(\mathrm{PhD})$ & 2.391 & $<0.0001$ & \\
\hline & $\beta 11$ (year.centred ${ }^{2}$ ) & -0.006 & $<0.0001$ & \\
\hline \multirow{7}{*}{$\begin{array}{l}\text { Sub-population } \\
\text { Descendants }\end{array}$} & & Estimate & $p$-value & $p$-model \\
\hline & $\beta 0$ (Intercept) & 0.545 & $<0.0001$ & $<0.0001$ \\
\hline & $\beta 1$ (year.centred) & 0.039 & 0.981396 & $R^{2}$ \\
\hline & $\beta 2$ (> 4-years) & 0.343 & $<0.0001$ & 0.9864 \\
\hline & $\beta 3(\mathrm{PhD})$ & -0.179 & $<0.0001$ & \\
\hline & $\begin{array}{l}\beta 12 \text { (year.centred. } \\
>4 \text {-years) }\end{array}$ & -0.008 & 0.0168 & \\
\hline & $\beta 13$ (year.centred $\cdot \mathrm{PhD}$ ) & -0.042 & $<0.0001$ & \\
\hline \multirow{7}{*}{$\begin{array}{l}\text { Sub-population } \\
\text { Norwegian } \\
\text { origin }\end{array}$} & & Estimate & $p$-value & $p$-model \\
\hline & $\beta 0$ (Intercept) & 0.994 & $<0.0001$ & $<0.0001$ \\
\hline & $\beta 1$ (year.centred) & 0.0005 & 0.455 & $R^{2}$ \\
\hline & $\beta 2$ (> 4-years) & -0.037 & $<0.0001$ & 0.9884 \\
\hline & $\beta 3(\mathrm{PhD})$ & -0.121 & $<0.0001$ & \\
\hline & $\begin{array}{l}\beta 12 \text { (year.centred } \\
>4 \text {-years) }\end{array}$ & -0.0002 & 0.827 & \\
\hline & $\beta 13$ (year.centred $\cdot \mathrm{PhD})$ & -0.012 & $<0.0001$ & \\
\hline
\end{tabular}

Source: Based on (Statistics Norway, 2016b).

"unknown" students may be international students and might not reflect the immigrant student body in Norway.

The proposed model for descendant participation trends significantly explains ( $p$-value $<0.0001)$ practically the entire variance $(98.84 \%)$. A substantial increase is evident over time (0.039) for the reference group, " $\leq 4$-years", highest main effect of equity for the " $>4$ years" track relative to " $\leq 4$ years" track, and a relative stability in the Ph.D. track reflected by a negative main effect and interaction with time that counter-balances the positive time effect. Descriptively the descendants point of origin is of slight under-representation and slowly, but constantly their representation rates increase in all tracks (but Ph.D.) to above equity level 1. 
The proposed model for the Norwegian origin group significantly explains ( $p$-value $<0.0001)$ the variance in its entirety $(98.84 \%)$. No main effect of time (reform years) is identified beyond random fluctuation $(p$-value $=0.455)$. There is a small negative main effect of "> 4 -years" and a larger one for "Ph.D.", enhanced by a negative interaction with time, i.e. at the Ph.D. level, students of Norwegian origin are slightly under-represented, a trend which has intensified over the years and may be correlated with increased immigrant participation. Thus, also in the case of Norway, similar trends are indicated. On the one hand the second-generation group has increased its proportional participation and on the other first-generation positive participation trend is reversed around 2005.

\section{Conclusions}

The study examined trends in immigrant participation in the three Scandinavian HE systems during a period of Europeanization reforms. Consistent with the immigrant paradox model examination has shown that persons with an immigrant background are either over-represented or very close to an equitable representation in all three Scandinavian countries. Outcomes are in line with previous findings for immigrant transition at the end of low secondary level. Furthermore, drawing on the cost-benefit model it was assumed that immigrant participation would be positively influenced by the introduction of shorter degrees. Moreover, the multiplier effect model suggests that second-generation immigrants are most likely to be positively affected by the reform and more diversified degrees. However, an in-depth examination of participation within the cycles reveals a multi-faceted picture of participation trends and diverse patterns for immigrants and descendants.

The Bologna Reform led to increased flexibility in Danish and Norwegian $\mathrm{HE}$ as a result of the introduction of the Bologna degree system. Consequently, an increase in the inclusion and proportional representation of persons with an immigrant background during the reform years is identified. Nevertheless, first-generation and second-generation immigrants should be examined as two separate groups with different characteristics as each group exhibits contrasting patterns which may point to different educational barriers and diverse analysis limitations: first-generation immigrants include international students, which may bias results; overall changes to the composition of this group (increased labour immigration, increased refugee immigration and more) may influence proportional representation rates in the short-term. Supplementary in-depth data on the composition of first-generation immigrant students, currently not available, may enable a more coherent understanding of the participation patterns of immigrants.

A more conclusive picture emerges for the second-generation immigrants (descendants), for whom a clear upward trend was identified in all three 
Scandinavian countries. These outcomes may point to an 'immigrant paradox' in the Scandinavian HE systems and to a multiple educational progress when more flexibility is introduced. Further research of the various sub-groups within the descendants may shed more light on whether this applies to all. Nonetheless, a more subtle form of inequality was found at the more advanced cycles. Inequality within the various programmes was not addressed due to data restrictions although further attention is required as the results indicate rather conclusively that the descendants are the groups that benefited the most from the changes in HE. Finally, future research directions may focus on the more elusive differences among sub-groups of persons with an immigrant background or participation trends within academic fields. Equally important remains the question as to whether the future entry into the labour market of the groups in question has improved as a result of increased higher academic attainment.

\section{Reference}

Arum, R., Gamoran, A., \& Shavit, Y. (2007). More inclusion than diversion: Expansion, differentiation, and market structure in higher education. In Y. Shavit, R. Arum, \& A. Gamoran (Eds.), Stratification in higher education: A comparative study. Stanford, CA: Stanford University Press.

Berton, F., \& Bondonio, D. (2014). The impact of degree duration on higher education participation: Evidence from a large-scale natural experiment (LABORatorio R. Revelli Working Papers Series 137. LABORatorio R. Revelli, Centre for Employment Studies.

Bondonio, D., \& Berton, F. (2018). The impact of degree duration on higher education participation: Evidence from a large-scale natural experiment. Oxford Bulletin of Economics and Statistics, 80(5), 905-930. Retrieved from https://doi.org/10.1038/ nrc2967.Questa

Busemeyer, M. R. (2018). Education and skills for inclusive growth. In C. Deeming, \& P. Smyth (Eds.), Reframing global social policy: Social investment for sustainable and inclusive growth (pp. 189-212) . Bristol: Policy Press.

Camilleri, A., Griga, D., \& Mühleck, K. (2013). Evolving diversity II: Participation of students with an immigrant background in European higher education. European Commission. Retrieved from http://www.pedocs.de/volltexte/2013/8281/

Cappellari, L., \& Lucifora, C. (2009). The "Bologna process" and college enrolment decisions. Labour Economics, 16(6), 638-647. Retrieved from https://doi.org/10.1016/j. labeco.2009.08.009

Crul, M., Schneider, J., Keskiner, E., \& Lelie, F. (2016). The multiplier effect: How the accumulation of cultural and social capital explains steep upward social mobility of children of low-educated immigrants. Ethnic and Racial Studies, 40(2), 1-18. Retrieved from https://doi.org/10.1080/01419870.2017.1245431

Darvas, Z., \& Wolff, G. B. (2016). An anatomy of inclusive growth in Europe. Brussels: Bruegel Blueprint 26. 
Di Pietro, G. (2011). The Bologna process and widening participation in university education: New evidence from Italy. Empirica, 39(3), 357-374. Retrieved from https:// doi.org/10.1007/s10663-011-9172-5

Docquier, F. (2018). Long-term trends in international migration: Lessons from macroeconomic model. Economics and Business Review, 4(1), 3-15.

Dollmann, J. (2017, March). Positive choices for all? SES- and gender-specific premia of immigrants at educational transitions. Research in Social Stratification and Mobility, 49, 20-31. Retrieved from https://doi.org/10.1016/j.rssm.2017.03.001

Feliciano, C., \& Lanuza, Y. R. (2017). An immigrant paradox? Contextual attainment and intergenerational educational mobility. American Sociological Review, 82(1), 211-241. Retrieved from https://doi.org/10.1177/0003122416684777

Griga, D., \& Hadjar, A. (2013). Migrant background and higher education participation in Europe: The effect of the educational systems. European Sociological Review, 30(3), 275-286. Retrieved from https://doi.org/10.1093/esr/jct031

Hofferth, S. L., \& Moon, U. J. (2016). How do they do it? The immigrant paradox in the transition to adulthood. Social Science Research, 57, 177-194. Retrieved from https://doi.org/10.1016/j.ssresearch.2015.12.013

Jonsson, J. O., \& Erikson, R. (2007). Sweden: Why educational expansion is not such a great strategy for equality-theory and evidence. In Y. Shavit, R. Arum, \& A. Gamoran (Eds.), Stratification in higher education: A comparative study. Stanford, CA: Stanford University Press.

Lindberg-Sand, Å. (2007). The Swedish Bologna process: Reckless race or revitalising reform?. Innsbruck: EAIR FORUM.

Maassen, P., \& Musselin, C. (2009). European integration and the Europeanisation of higher education. In A. Amaral, G. Neave, C. Musselin, \& P. Maassen (Eds.), European integration and the governance of higher education and research (pp. 3-14). Dordrecht: Springer.

Mailand, M. (2017). Global issues refugees and labour in Europe. The European refugee crisis and the reaction of labour market actors: The case of Denmark. Global Labour Journal, 8(1), 90-98.

Marginson, S. (2011). Equity, status and freedom: A note on higher education. Cambridge Journal of Education, 41(1), 23-36. Retrieved from https://doi.org/10.1 080/0305764X.2010.549456

Marginson, S. (2016). The worldwide trend to high participation higher education: Dynamics of social stratification in inclusive systems. Higher Education, 72(4), 413-434. Retrieved from https://doi.org/10.1007/s10734-016-0016-X

Neugebauer, M., Neumeyer, S., \& Alesi, B. (2016). More diversion than inclusion? Social stratification in the Bologna system. Research in Social Stratification and Mobility, 45, 51-62. Retrieved from https://doi.org/10.1016/j.rssm.2016.08.002.

OECD. (2017). International migration database foreign workers. Retrieved from https:// doi.org/http://dx.doi.org.000066al25a6.han3.ue.poznan.pl/10.1787/data-00342-en

OECD. (2018). Catching up? Intergenerational mobility and children of immigrants. Paris: OECD Publishing. Retrieved from https://doi.org/10.1787/9789264288041-en

Pettersen, S. V., \& Østby, L. (2013). Immigrants in Norway, Sweden and Denmark. Samfunnsspeilet, 5, 76-83. 
Radaelli, C. M. (2002). The domestic impact of European Union public policy: Notes on concepts, methods, and the challenge of empirical research. Politique Européenne, $1,105-136$.

Sin, C., \& Saunders, M. (2014). Selective acquiescence, creative commitment and strategic conformity: Situated national policy responses to Bologna. European Journal of Education, 49(4), 529-542. Retrieved from https://doi.org/10.1111/ejed.12072

SSB. (2017). Immigrants and Norwegian-born to immigrant parents, 1 January 2017. Retrieved from http://www.ssb.no/en/befolkning/statistikker/innvbef/aar/201503-04

Statistics Denmark. (2016). Population 1. January by citizenship, ancestry and time. Retrieved June 20, 2016 from http://www.statbank.dk/10021

Statistics Denmark. (2017). Full-time education. Retrieved December 4, 2017 from http://www.statbank.dk/statbank5a/default.asp?w=1366

Statistics Norway. (2016a). Immigrants and Norwegian-born to immigrant parents, by country background, time and contents. Retrieved June 22, 2016 from https://www. ssb.no/statistikkbanken/selectvarval/saveselections.asp

Statistics Norway. (2016b). National student register.

Statistics Sweden. (2016). Foreign-born persons by country of birth and year. Retrieved June 22, 2016, from http://www.statistikdatabasen.scb.se/pxweb/en/ssd/START BE_BE0101_BE0101E/UtrikesFoddaR/table/tableViewLayout1/?rxid=42e118b92100-47ce-906f-de7399151b9b

Statistics Sweden. (2017). Register on participation in education. Retrieved December 4, 2017 from http://www.statistikdatabasen.scb.se/pxweb/en/ssd/

Thomson, R. (2017). Explaining inequality? Rational action theories of educational decision making. In A. Mountford-Zimdars, \& N. Harrison (Eds.), Access to higher education: Theoretical perspectives and contemporary challenges. Oxon: Routledge.

Vukasoavić, M. (2013). Change of higher education in response to European pressures: Conceptualization and operationalization of Europeanization of higher education. High Education, 66(3), 311-324. Retrieved from https://doi.org/10.1007/ s10734-012-9606-4 